EETP Vol. 14, 2019, №. 2(52)

ISSN $1896-2327$ / e-ISSN 2353-7787

DOI: $10.35765 /$ eetp.2019.1452.08

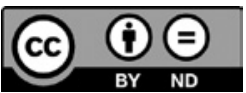

Nadesłano: 26.01.2019

Zaakceptowano: 27.02.2019

Sugerowane cytowanie: Ludwiczak J.S., Przez gryzmolenie do kultury wizualnej. Książka Jana Bajtlika Typogryzmol jako narzędzie wspierania kompetencji wizualnych dziecka, „Edukacja Elementarna w Teorii i Praktyce”, vol. 14, nr 2(52), s. 121-132. DOI: $10.35765 /$ eetp.2019.1452.08

Joanna S. Ludwiczak

ORCID: 0000-0002-2072-4685

Uniwersytet Łódzki, Wydział Nauk o Wychowaniu, Katedra Edukacji Artystycznej i Pedagogiki Twórczości

\title{
Przez gryzmolenie do kultury wizualnej. Ksiq̨żka Jana Bajtlika Typogryzmol jako narzędzie wspierania kompetencji wizualnych dziecka
}

\section{Through Doodling to Visual Culture. Alphadoodler by Jan Bajtlik as a Tool for Supporting Child's Visual Competences}

\section{SŁOWA KLUCZOWE ABSTRAKT \\ alfabetyzacja wizualna, \\ kompetencje wizualne, książka aktywnościowa, dziecko odbiorca, dziecko współtwórca, sztuka dla dzieci, typografia, Jan Bajtlik \\ Obrazkowy charakter współczesnej kultury zainicjował sygnalizowa- ny przez coraz większą liczbę badaczy postulat pilnej potrzeby kształ- cenia kompetencji wizualnych już od najmłodszych lat. Do otoczenia dziecka trafia ogromna ilość bodźców wizualnych, wśród których mieszają się różne jakości wizualne: infantylne wzorce i wartościowe artefakty. Celem artykułu jest próba interpretacji formalno-treściowej książki Jana Bajtlika Typogryzmol jako przykładu sztuki dla dzieci wprowadzającej odbiorcę w świat kultury wizualnej. Jakościowa ana- liza wybranych cech książki aktywnościowej przeprowadzona zosta- ła metodą interpretacji kompozycyjnej wywodzącej się z krytycznej metodologii badań nad wizualnością. Na podstawie koncepcji Gilian Rose odniesiono się do wybranych zagadnień z obszaru samej książki jako obiektu sztuki, a także niektórych aspektów z obszaru jej wytwa- rzania (w szczególności kontekst autora) oraz odbiorczości (potencjal- ne znaczenie). Wnioski przeprowadzonej interpretacji odwołują się do waloryzacji książki aktywnościowej w kontekście jej doświadczania przez dziecko.}




\title{
KEYWORDS ABSTRACT
}

visual literacy, Pictographic nature of modern culture initiated the demand for develvisual competences, oping visual competences in children starting from early age, which activity book, has been mentioned by an increasing number of researchers. A child's child recipient, child co-creator, art for children, typography, Jan Bajtlik environment contains a great quantity of visual stimuli, among which various visual qualities are mixed, i. e. infantile patterns and valuable artefacts. The purpose of this work is to take an attempt at interpreting "Alphadoodler" by Jan Bajtlik in terms of its form and contents as an example of art for children which introduces its audience into the world of visual culture. The qualitative analysis of the selected properties of the activity book was conducted using the method of compositional interpretation, which originates from the critical methodology of visual research. Based on the concept by Gilian Rose, selected issues from the book itself as an object of art, as well as certain aspects related to its production (context of the author) and its receipt (possible meaning) are discussed. The conclusions of the interpretation refer to the valuation of the activity book in the context of it being experienced by a child.

\section{Wizualność w otoczeniu dziecka}

Obrazy zakotwiczone w otaczającej przestrzeni są znamienną cechą współczesnej nam kultury. Za pośrednictwem różnorodnych technologii przeniknęły do wszystkich sfer codziennej rzeczywistości i trudno zaprzeczyć ich oddziaływaniu na kulturowe kształtowanie życia społecznego. Zjawisko to dotyczy także otoczenia, w którym wzrasta dziecko. W dobie wzrokocentryzmu (Banks 2013: 39-40) nieukształtowany mały odbiorca wykazuje całkowitą bezbronność wobec ogromu napływających zewsząd bodźców wizualnych, wymierzonych w jego uwagę. Należy zaznaczyć, że małe dziecko kształtuje swoje upodobania przede wszystkim na podstawie utrwalonych wzorców. Bywa, że wizerunki plastyczne widywane we wczesnych latach pozostają z nami na całe życie, warunkując przyszłe wybory estetyczne (Szuman 1951; Ungeheuer-Gołąb 2015). Zdaniem Stefana Szumana otaczające nas obrazy

\begin{abstract}
w swoisty sposób modelują i kształtują naszą wyobraźnię. To, co nam najczęściej pokazywano, gdy byliśmy jeszcze dziećmi - więc obrazy, które wisiały na ścianach w domu naszych rodziców czy w szkole lub obrazki, które znajdowały się w naszych pierwszych książkach - to wszystko zaciążyło na naszej wyobraźni i to właśnie w mniejszej lub większej mierze w niej się utrwaliło (Szuman 1951: 10).
\end{abstract}

Percepcja wzrokowa jest dla małego dziecka narzędziem pozwalającym zaspokoić naturalną ciekawość świata. Nie ulega zatem wątpliwości, że wszystko, co znajduje się w zasięgu wzroku, może mieć istotny wpływ na rozwój wielu sfer dziecięcej 
osobowości. Za kreowanie najbliższego otoczenia dziecka pełną odpowiedzialność ponoszą dorośli (rodzice, nauczyciele), którzy konstruują dziecięcą przestrzeń zgodnie z własnym wyobrażeniem dzieciństwa (Klus-Stańska 2007). Jak wynika z raportu opublikowanego w 2017 roku przez Narodowe Centrum Kultury (NCK/GFK 2018), dotyczącego kulturalnych wyborów opiekunów dzieci, preferencje w zakresie estetyki książek i innych produktów dla dziecka często dyktowane są przez media ekranowe. Autorzy raportu podają, że rodzice w swoich wyborach polegają na upodobaniach dziecka i w pierwszej kolejności pragną zaspokoić jego oczekiwania. Najchętniej sięgają po artykuły (w tym książi) opatrzone etykietami podkreślającymi ich walor edukacyjny oraz te, które klasyfikują jako „ładne”, „przyjemne”, „kolorowe” i wyzwalające wyłącznie pozytywne emocje. Przytoczone badania potwierdzają powszechność zinfantylizowanej wizji dzieciństwa obecnej zarówno w świadomości rodziców, nauczycieli, jak i w samych przedmiotach trafiających do otoczenia dziecka (książkach, zabawkach itd.). Tak zwany „przemysł dziecięcy” przepełniony jest produktami spersonalizowanymi i jednoznacznie określającymi adresata. Zabiegi te, w pierwszej chwili sugerujące nastawienie na prawomocność dziecka, są jednak w znacznej mierze częścią strategii wytwarzania potrzeb konsumenckich już u najmłodszych.

W refleksji naukowej pojawiają się głosy podkreślające marginalizowanie w praktyce pedagogicznej zagadnienia percypowania przez dziecko naocznych cech przestrzeni materialnej wraz z wpisanymi w nią przedmiotami (por. Cackowska 2014). Obrazkowy charakter współczesnej kultury zainicjował sygnalizowany przez coraz większą liczbę badaczy postulat pilnej potrzeby kształcenia kompetencji wizualnych. Są oni zgodni, że rozwijanie wspomnianych umiejętności określane jako alfabetyzacja wizualna powinno stać się obowiązkowym zadaniem w edukacji dziecka, stwarzającym przestrzeń dla nabywania zdolności wyodrębniania i interpretacji komunikatów wizualnych, a także ich wartościowania, krytycznego osądu, jak również tworzenia własnych znaków i komunikatów wizualnych (zob. Pater-Ejgierd 2010; Dylak 2012). Kształtowanie kompetencji rozumiane jako ciągły i długotrwały proces prowadzący do zdobycia wiedzy, nabywania umiejętności i kreowania cech osobowości w odniesieniu do edukacji wizualnej oznacza „umiejętność twórczej percepcji i ekspresji (...), umiejętność oceniania - gust estetyczny (...), wrażliwość społeczno-moralną (...), wrażliwość estetyczną (...), świadomość funkcji sztuki w życiu człowieka (...), postawę szacunku do piękna i sztuki” (Mazepa-Domagała, Wilk 2015: 92-93). Osiągnięcie wymienionych kompetencji może się odbywać na drodze percypowania wytworów sztuki oraz ekspresji własnej dziecka.

Rudolf Arnheim, manifestujący potrzebę zwrotu ku szeroko pojętemu myśleniu wizualnemu, stwierdza, że w życiu codziennym konieczny jest jak najszerszy dostęp do sztuki. To od niej należy uczyć się „nadawania formy wizualnej wszystkim aspektom życia”. Autor przypisuje sztuce znaczące funkcje i nazywa ją „potężnym narzędziem 
wzmacniania zdolności postrzegania, bez której twórcze myślenie nie jest możliwe w żadnej dziedzinie" (Arnheim 2011: 11). Zawarta w obrazach plastyczna wizja świata w postaci przekazu ikonicznego - symboli, kodów, znaków - trafia do odbiorcy za pośrednictwem języka sztuki. Jego poznanie wymaga świadomego kształtowania, między innymi poprzez motywację do obcowania z dziełami sztuki. Doświadczanie sztuki odwołuje się do humanistycznej kultury odbiorcy, oddziałuje na zmysł wzroku, wspiera procesy spostrzegania i ujmowania świata, pobudza i aktywizuje wyobraźnię, wyzwala emocje, rozwija wrażliwość (Uberman 2005: 364-365). Kontakt ze sztuką wpływa na zintensyfikowanie percepcji odbiorcy poprzez wyjście poza standardowy ogląd przedstawień wizualnych. Jest to wynikiem kreowania przez twórcę utworu plastycznego na podstawie subiektywnej interpretacji podjętego tematu. Pierwotne funkcje dzieła sztuki może spełniać odpowiednio dobrana ilustracja książkowa, z którą dziecko w sposób naturalny obcuje podczas zabawy i nauki (Boguszewska 2015: 127).

\section{Sztuka w książce dla dziecka}

Obrazy najczęściej współistnieją w zestawieniu z tekstem pisanym (Rose 2010: 31), który także może znacząco ingerować w widzialny charakter otoczenia poprzez swoje znaczeniowe oraz formalne właściwości. Słowa mogą przybierać postać prezentacji wizualnej lub przenikać się z obrazem w przekazach multimodalnych (Dylak: 121). Nawet małe dzieci, które nie opanowały jeszcze umiejętności pisania i czytania, świetnie rozpoznają logotypy swoich ulubionych marek sygnujące rozmaite, dedykowane im produkty. Przykład ten dowodzi, że litery zebrane w słowa oglądane są przez dziecko jako obrazy - poprzez pryzmat jakości plastycznych, takich jak: linia, kształt, barwa, kontrast itp. Mamy tu do czynienia ze specyficznym typem odbioru polegającym na patrzeniu na wygląd tekstu, a nie na zawarte w nim znaczenia. W takiej konwencji powstają książki dla najmłodszych, gdzie warstwa werbalna i wizualna łączą się nierozerwalnie, tworząc wzajemne relacje. Słowo pisane ulega materializacji i zyskuje swój plastyczny wydźwięk. Kategoria logowizualności książek tego gatunku wyraża się rzetelnym opracowaniem typograficznym, czyli odpowiednim doborem lub zaprojektowaniem kroju pisma, określeniem wielkości liter, ich zagęszczenia, koloru, ekspresji, proporcji, kompozycji itd. Zabiegi te „ułatwiają (...) rozpoznanie samego znaku typograficznego, który dla dziecięcego odbiorcy nie jest przezroczysty, nie odsyła wprost, bezpośrednio i automatycznie do abstrakcyjnej treści, myśli lub pojęcia” (Karpowicz 2013: 179).

Dobrze zaprojektowana książka, będąc niepodważalnym przykładem sztuki użytkowej, łączy kilka dziedzin projektowania graficznego, a w szczególności grafikę wydawniczą, ilustrację i wspomnianą już typografię. W najlepszych projektach książek wszystkie elementy treści, formy i edytorstwa podporządkowane są spójnej koncepcji. 
Specyfika kontaktu z obiektem, jakim jest książka, sprawia, że może ona się stać szczególnie wartościowym medium w kształtowaniu kompetencji wizualnych dziecka, niosąc pożyteczny wpływ na wszechstronny rozwój jego osobowości. Liczni autorzy zgodnie podkreślają aksjologiczne znaczenia obrazu w książce dedykowanej najmłodszemu odbiorcy (Szuman 1951: 13-22; Iwanicka 2009: 309; Boguszewska 2015: 127; Centner-Guz 2017: 73-75). Tymczasem dane z badań NCK (NCK/GFK 2018) wskazują na niezrozumienie i wyraźną niechęć opiekunów i rodziców wobec propozycji o walorach artystycznych, jak np. książka Tam gdzie żyją dzikie stwory Maurice’a Sendaka (2014), które respondenci postrzegają jako: „dziwne”, „brzydkie”, „nie dla dzieci”.

\section{Książka akływnościowa jako obiekt wizualny - możliwości badawcze}

Każdy przejaw wizualnej rejestracji fragmentów świata jest jego interpretacją i nie ukazuje go takim, jaki jest naprawdę, co w konsekwencji przekłada się na liczne możliwości odbioru i tworzenia znaczeń. Jak postuluje wielu badaczy w dziedzinie nauk społecznych (m.in. Silverman 2008; Rose 2010; Sztompka 2012; Banks 2013), obrazy nie powinny być bagatelizowane w refleksji naukowej, ponieważ ich analiza może przynieść cenne rezultaty poznawcze, szczególnie „w odkrywaniu nieznanych lub niebranych wcześniej pod uwagę wymiarów życia społecznego" (Banks 2013: 199). Gilian Rose przyjmuje istnienie trzech obszarów, w obrębie których tworzone są znaczenia obszar wytwórczości, obszar samego obrazu (obiektu wizualnego) i obszar odbiorczości. Każdy z nich można rozpatrywać bardziej szczegółowo w trzech modalnościach: technologicznej, kompozycyjnej i społecznej (Rose 2010: 33-48). W prezentowanych rozważaniach trudno jednoznacznie zakreślić wyraźne granice analizowanych obszarów. Rozważania skupiają się zarówno na samym obiekcie wizualnym (właściwościach formalnych, treści), obszarze jego wytwarzania (kontekście autora, technikach), jak i obszarze odbioru (potencjalnego oddziaływania na odbiorcę). Analiza przeprowadzona została na podstawie metody interpretacji kompozycyjnej (Rose 2010: 62-73).

Przedmiotem prezentowanej refleksji jest książka aktywnościowa Jana Bajtlika Typogryzmol (Bajtlik 2014) rozpatrywana jako materialny obiekt wizualny. Podczas wyboru przedmiotu badań decydującym parametrem było kryterium wyjątkowości w skali polskich książek aktywnościowych dla dzieci, a nawet polskich książek dla dzieci w ogóle. Publikacja ta zdobyła międzynarodowe uznanie, co potwierdza uhonorowanie autora nagrodą w kategorii „Non Fiction” w ramach „Bologna Ragazzi Award” w 2015 roku - najbardziej prestiżowym na świecie wyróżnieniem w dziedzinie ilustracji i książki dla dzieci (http://www.bolognachildrensbookfair.com/en/ home/878.html [dostęp: 30.10.2018]). Książka Typogryzmol ukazała się w sześciu językach: polskim, angielskim, włoskim, francuskim, hiszpańskim i katalońskim. 
Celem podjętych badań jest próba formalno-treściowej analizy książki Jana Bajtlika jako przykładu sztuki dla dzieci, wprowadzającej odbiorcę w świat kultury wizualnej. Główny problem badawczy zawiera się w pytaniu: jakie aspekty książki aktywnościowej Typogryzmol mogą wspierać nabywanie kompetencji wizualnych przez dziecko?

Termin książka aktywnościowa (ang. activity book) obecny jest przede wszystkim w publicystycznym obiegu dotyczącym tematyki książki i ilustracji książkowej dla dzieci, jak np. na stronach księgarń internetowych, blogach, forach internetowych itp. Z reguły oznacza publikację, której rozkładówki przybierają postać kart z zadaniami do wykonania i prowokują aktywność odbiorcy, jak np. wyszukiwanie elementów, wodzenie dłonią po kształtach, projektowanie, wklejanie, dorysowywanie itd. Wśród wielu odmian książek aktywnościowych szczególne miejsce zajmują książki do aktywności plastycznej. W polskiej ofercie wydawniczej odnaleźć można wiele godnych uwagi książek, zachwycających zarówno szatą graficzną, jak i twórczo podjętym tematem (zob. Lange 2007; Bogucka, Tomiło 2014; Matoso 2015; Styszyńka, Koziński 2015; Czerniak-Chojnacka 2017).

\section{Obszar wytwarzania - kontekst autora i technologii}

Zarówno sposób, jak i okoliczności powstania czy też wytwarzania dokumentów wizualnych mogą znacząco wpływać na ich wygląd i wywierane przez nie skutki (Rose 2010: 34).

W pierwszej kolejności należy wspomnieć o kontekście autora, ponieważ to zamysł jego koncepcji, proces twórczy i warsztat składają się na ostateczną postać książki.

Jan Bajtlik urodził się w 1989 roku. Studia ukończył na Akademii Sztuk Pięknych w Warszawie, gdzie pracuje nad rozprawą doktorską. W swoim dorobku artystycznym posiada wiele nagród, ma na koncie liczne wystawy polskie i zagraniczne. Bajtlik uważany jest za jednego z najbardziej rozpoznawalnych polskich grafików młodego pokolenia. Jest artystą multidyscyplinarnym i mimo że z powodzeniem realizuje się w wielu dziedzinach sztuki, to ilustrację i projektowanie książek dla dzieci traktuje bardzo poważnie. Choć, jak sam podkreśla, nie uczestniczył nigdy w kursach pedagogicznych, wstępne rozkładówki książki Typogryzmol weryfikował podczas warsztatów plastycznych dla dzieci. Podczas licznych spotkań zbierał informacje dotyczące właściwego rozumienia poleceń, poprawności interpretacji syntetycznych form graficznych, dostateczności przestrzeni pozostawionej dziecku (Bajtlik 2016). Zdaniem Bajtlika to właśnie „zaprojektowanie pustki, bieli, która ma być dla odbiorcy polem do stworzenia obrazu” jest „kluczową kwestią w tworzeniu książki aktywnościowej” (Bajtlik 2016: 31). 
Wyraz artystyczny książki Typogryzmol ściśle związany jest z indywidualnym stylem Bajtlika i wyraźnymi inspiracjami polską szkołą plakatu oraz przestrzenią miasta, choć widoczne są także odwołania do sztuki dziecka. Autor do stworzenia ilustracji wykorzystał różne techniki rysunkowe i graficzne, zarówno klasyczne (druk wypukły, rysunek pastelą, rysunek tuszem, kolaż), jak i komputerowe (grafika wektorowa, fotografia).

Wiele cech wizualnych Typogryzmota, jak np. rozkład tekstu i ilustracji oraz zależności słowa i obrazu, są właściwościami charakteryzującymi utwory z gatunku książki aktywnościowej. Ich warstwa werbalna ma zazwyczaj formę krótkich instrukcji dla odbiorcy, a poszczególne rozkładówki zawierają przestrzeń na działania odbiorcy - rysowanie, projektowanie, wylepianie, wycinanie, zaznaczanie itd.

\section{Struktura kompozycyjna - kontekst treści i formy}

$\mathrm{Na}$ ostateczny kształt książki składa się wiele komponentów związanych z jej formą i treścią, które G. Rose ujmuje jako strukturę kompozycyjną (Rose 2010: 62). Cechy formalne książki to elementy, które już od pierwszych chwil oddziałują na zmysły czytelnika. Format, okładka, oprawa, papier, kolorystyka, ilustracje, typografia, kompozycja rozkładówek - wszystko to może wywołać chęć dalszej eksploracji lub pozostawić odbiorcę obojętnym.

Książka Bajtlika rozmiarem zbliżona jest do formatu A4, zawiera ponad 70 rozkładówek na dobrej jakości papierze. Oprawiona jest w miękką okładkę ze skrzydełkami na dwóch trzecich szerokości, dzięki czemu całość zyskuje dodatkowy sznyt. $\mathrm{Z}$ zewnątrz okładkę wyróżnia kontrastowa grafika przykuwająca uwagę intrygującym zestawieniem czarno-białych kształtów (liter) na fluoroscencyjnym, pomarańczowym tle. Wnętrze okładki przedstawia polski alfabet - wielkie i małe litery zapisane białą, bezszeryfową, linearną antykwą na jaskraworóżowym tle. Konsekwentna oszczędność kolorów zachowana została także na stronie tytułowej i kolejnych rozkładówkach. Na białym the (za wyjątkiem kilku stron z czarnym, szarym, fioletowym, jaskrawopomarańczowym tłem) pojawiają się przedstawienia monochromatyczne (w czerni, bieli, szarościach, fiolecie oraz jaskrawozielonym i jaskrawopomarańczowym) lub dwukolorowe (np. oranż i czerń, fiolet i czerń, zieleń i czerń). Ilustracje zrealizowane są w różnych konwencjach, wynikających z zastosowanych technik. Przybierają postać surowych w formie wektorowych przedstawień, jak np. geometryczne obrysy o „technicznym” charakterze czy rytmiczne układy znaków. Innym razem przypominają swobodny, odręczny rysunek dziecka lub zabawy w stemplowanie i wycinanki. Niektóre z ilustracji mają postać fotografii poddanej desaturacji (pejzaż ośnieżonych szczytów gór, słupy teatralne na tle przestrzeni miejskiej, opakowania produktów), inne nawiązują do 
estetyki komiksu (ilustracja wnętrza pokoju, sylweta „smokozaura”). Kompozycja rozkładówek podporządkowana jest zadaniom stawianym odbiorcy. W jednym przypadku ilustracja wypełnia całą powierzchnię obu sąsiadujących stron, a innym razem zawiera jedynie kilka niewielkich elementów, pozostawiających większość miejsca na działania plastyczne dziecka. Polecenia, które towarzyszą ilustracjom, umieszczone są najczęściej w górnej części stron parzystych, rzadziej nieparzystych, a niekiedy wpisane są w kształt ilustracji. Krój pisma zastosowany do warstwy tekstowej nawiązuje do pisma odręcznego wykonanego flamastrem, w połączeniu z bezpośrednimi sformułowaniami tworzy komunikaty o czytelnym przekazie i partnerskiej wymowie.

Tematem przewodnim analizowanego utworu jest typografia, którą można rozumieć jako nadawanie wizualnych właściwości formom pisanym. Typografia jest dziedziną grafiki użytkowej zajmującą się szeroko rozumianym projektowaniem tekstu (od litery po układy tekstowe), choć terminu tego używa się także dla określenia cech formalno-obrazowych tekstu, np. w publikacji, na plakacie. W książce Typogryzmol w warstwie ilustracyjnej niemalże na każdej stronie pojawiają się litery lub znaki interpunkcyjne o różnych stopniach (wielkościach), należące do rozlicznych krojów pism - od klasycznych antykw do typografii eksperymentalnej. Znaki te stają się dla odbiorcy pretekstem do tworzenia plastycznych wizerunków, np. cyrkowców, wieżowców, portretów postaci, znanych budowli. Litery przekształcają się w przynęty na ryby, koła pojazdów, domowe sprzęty i meble, zwierzęta, pnie drzew, profile twarzy itd. Tematyka książki jest uniwersalna i obejmuje m.in. wątki związane z fauną, pojazdami, czasem wolnym, sportem, projektowaniem graficznym (plakat, logo, projektowanie opakowań, kroju pisma, okładki książki itp.). Treść analizowanego utworu dotyka zarówno zagadnień bliskich i znanych dziecku (np. portret rodziców), zabawy (np. odkopywanie liter spod śniegu), świata fantazji (np. „smokozaur”, rozmowa budynków), potencjalnych lęków (np. robaki), jak i bardziej odległych, np. starożytne pismo, słynne budowle, sztuka w przestrzeni miejskiej.

\section{Typogryzmol jako sztuka dla dzieci - kontekst odbiorcy}

Typogryzmol jest publikacją dedykowaną dzieciom powyżej czwartego roku życia bez względu na płeć, jednak w przypadku dzieci w wieku przedczytelniczym wymagany jest pośrednik przekazujący treść poleceń. Jak stwierdza sam twórca, jest to „książka dla dzieci, które znają alfabet dobrze, średnio albo wcale” (Bajtlik 2016: 31). Różnorodność kształtów i skali liter pozwala obserwować ich morfologiczne cechy, w tym różnice i podobieństwa. Książka daleka jest od podręcznika prowadzącego przez kolejne szczeble wiedzy i umiejętności. Sekwencja kolejnych przedstawień nie jest adekwatna do poziomu trudności zadań. Brak paginacji dodatkowo podkreśla brak rygoru linearnego odczytu. 
Książka będąca przedmiotem rozważań może być traktowana jako rodzaj komunikatu nadanego przez twórcę do dziecięcego odbiorcy. Zamieszczony na rewersie okładki tekst ma postać zaproszenia do wejścia w „świat typografii”, a jednocześnie wyjaśnienia tytułu i przesłania książi: „TY jesteś współtwórcą tej książki: rysujesz, malujesz, bawisz się kształtami liter i uczysz się pisać. TYPO bo typografia to projektowanie i układanie liter. TYPOGRY czyli zabawy literami. GRYZMOL i rysuj z rozmachem, tak jak ci się podoba”. Słowa te kierowane bezpośrednio do dziecka są deklaracją interakcji z odbiorcą oraz świadectwem partnerskiego traktowania go jako współtwórcy ksiązki. Autor za pośrednictwem poleceń oferuje przestrzeń dla nieskrępowanej dziecięcej kreatywności. Podejmuje z odbiorcą swoistego rodzaju artystyczną grę, zachęcając do swobodnego kreślenia, zabawy i eksperymentowania. Zadania w książce Typogryzmol pozostawiają znaczną dowolność, np. „Zrób zwierzęta z liter a. Zacznij od rysowania ogonów" i nie zawsze narzucają sposób ich wykonania, np. „Uwaga! Teren budowy! Pomóż budowniczym postawić dom”.

Wiele ilustracji jest, jak można przypuszczać, w zamierzeniu autora niedoskonałych (efekty „niedodruku”, odcisk palca, swobodne „bazgroły”, zdjęcia obdrapanych słupów itp.). Zabiegi te mogą zaintrygować odbiorcę, jak również ośmielić go do wyzbycia się lęku przed tym, „że coś nie wyjdzie”, a przypadkowe i niechciane elementy można przekształcić w nową wartość. W jednym z artykułów Bajtlik mocno krytykuje syndrom kolorowanki, który wyraża się w podporządkowaniu konturowi i utrwala strach przed wyjściem poza linię i podejmowaniem samodzielnych decyzji. Podkreśla także, że często obserwował u uczestników warsztatów niezadowolenie z efektów pracy, a „danie upustu emocjom w formie plastycznej, często przynosiło świetne rezultaty" (Bajtlik 2016: 26). Przytoczone refleksje świadczą o pewnym rodzaju społecznej odpowiedzialności twórcy Typogryzmola, co potwierdza również jego zaangażowanie w realizację warsztatów plastycznych i projektowych rozwijających założenia koncepcyjne książki. Przybrały one postać realizowanego w bibliotekach, przedszkolach, szkołach i placówkach kultury projektu edukacyjnego, w którym wzięło udział około 2000 dzieci w wieku 4-14 lat.

Przeprowadzona analiza daje liczne powody, by sądzić, że ambitne książki aktywnościowe, tworzone przez artystów, mogą stanowić wartościowe medium w kształtowaniu kompetencji wizualnych dziecka. Książka Bajtlika hołduje sztuce użytkowej, wywodzącej się z codzienności, przez co nawiązuje do pragmatycznego wymiaru sztuki. W naturalny sposób wprowadza dziecko w zagadnienia współczesnej kultury i sztuki. Inspiruje do obserwacji wizualnych aspektów otoczenia i obiektów, które je tworzą. Tematyka książki często odwołuje się do bliskiej i dalszej przestrzeni życiowej potencjalnego odbiorcy oraz wyznacza obszary nowych doświadczeń, wzbudzając zaciekawienie poznawcze. Dziecko w propozycjach kolejnych ćwiczeń, ujętych w formie zabawy, zachęcane jest do kreacji. Otrzymuje przy tym całą paletę środków języka plastycznego. 
Autor nie narzuca odbiorcy jedynej, właściwej odpowiedzi, obarczonej określonymi oczekiwaniami. Dziecko zyskuje poczucie sprawczości poprzez możliwość tworzenia własnych ilustracji, na podstawie własnej wyobraźni. Najważniejszym aspektem wartościującym Typogryzmol wydaje się doświadczenie estetyczne dziecka w akcie aktywnego odbioru książki. Dlatego też przejaw zaufania autora do dziecka jako współtwórcy rozpatrywać można w kontekście wspierania jego podmiotowości. Na pierwszym planie doświadczenia estetycznego w ujęciu Johna Deweya znajduje się „znamienna i dynamiczna relacja, której sens tkwi w tym, że jest aktualizowana przez nadawcę i odbiorcę" (Sztobryn 2007: 104). Zaciera się w ten sposób podział na dorosłego i dziecko, następuje demokratyzacja autora i odbiorcy.

\section{Refleksja końcowa}

We współczesnym otoczeniu dziecka dominują obrazy utrwalające sztampowe formy, stereotypowe wzorce, banalną estetykę i sentymentalną treść. Ich oddziaływanie może wyrządzić dziecięcej wrażliwości wiele krzywdy, o czym w sposób dosadny pisze Małgorzata Cackowska (2014: 274-275). Autorka wymienia szereg przejawów infantylizacji przestrzeni wizualnej dziecka, które przekładają się na dominację kiczu w jego codzienności i znaczących kontekstach rozwoju. Zdaniem Cackowskiej „uwiedzione tandetą dziecko, gwałcone estetycznie, rośnie «uszczęśliwione kiczem» i w kiczu dojrzewa, aby w przyszłości zaoferować swoim dzieciom ten sam rodzaj bycia w kulturze i te same doświadczenia estetyczne" (Cackowska 2014: 281).

Zmysł wzroku ma dla rozwoju dziecka „fundamentalne znaczenie, ponieważ dzięki niemu dziecko "otwiera się» na świat i «bierze go» w posiadanie, pomnaża i gromadzi informacje, wzbogaca wrażliwość i wyobraźnię, ulega przeżyciom” (Marciniak 1979: 257). Poprzez percepcję i ekspresję plastyczną mały odbiorca rozwija zdolność spostrzegania i wzbogaca własne doświadczanie świata.

Alternatywą dla masowo wydawanych książek mogą być utwory tworzone z szacunkiem do najmłodszego odbiorcy; znakomitym przykładem jest Typogryzmol. Utwór oferuje całe bogactwo jakości estetycznych i różnorodnych kodów wizualnych. Posiada niezaprzeczalny potencjał jako narzędzie alfabetyzacji wizualnej, a także oferuje dziecku wolność twórczą, wzmacniając jego osobistą tożsamość. Znakomicie wpisuje się we współczesną tendencję przeobrażania sztuki dla dziecka w sztukę współtworzoną z dzieckiem.

\section{Materiał źródłowy}

Bajtlik J. (2014). Typogryzmol, Warszawa: Wydawnictwo Dwie Siostry. 


\section{Bibliografia}

Arnheim R. (2011). Myślenie wzrokowe, tłum. M. Chojnacki, Gdańsk: Wydawnictwo Słowo/Obraz/Terytoria.

Bajtlik J. (2016). Psucie tęczy. O warsztatach plastycznych dla dzieci, których kreatywność bywa ttumiona na kolejnych szczeblach edukacji, „2+3 D. Grafika Plus Produkt”, nr 1, s. 24-31.

Banks M. (2013). Materiaty wizualne w badaniach jakościowych, tłum. P. Tomanek, Warszawa: Wydawnictwo Naukowe PWN.

Bogucka K., Tomiło S. (2014). Wytwórnik Kulinarny, Warszawa: Wydawnictwo Wytwórnia.

Boguszewska A. (2015). Forma książki wychowuje. O twórczości polskich artystów książki dla dzieci w świetle nagród Konkursu Polskiego Towarzystwa Wydawców Książek (19892010), [w:] A. Boguszewska, B. Niścior (red.), Sztuka i edukacja. Muzyka i sztuki plastyczne, Lublin: Wydział Artystyczny, Uniwersytet Marii Curie-Skłodowskiej.

Cackowska M. (2014). Wzrastać radośnie w przedszkolnym i szkolnym kiczu. Pytania o wspótczesną alfabetyzację wizualną dzieci, [w:] D. Klus-Stańska (red.), (Anty)edukacja wczesnoszkolna, Kraków: Oficyna Wydawnicza Impuls.

Centner-Guz M. (2017). Wartości ilustracji w książce obrazkowej i ilustrowanej w perspektywie porządku jej udostępniania dzieciom, „Edukacja Elementarna w Teorii i Praktyce”, vol. 12, nr 3 (45), s. 69-87.

Czerniak-Chojnacka D. (2017). Gotujemy, Warszawa: Babaryba.

Iwanicka K. (2009). Habent sua fata libelli, [w:] G. Leszczyński, D. Świerczyńska-Jelonek, M. Zając (red.), Ocalone królestwo. Twórczość dla dzieci-perspektywy badawcze - problemy animacji, Warszawa: Wydawnictwo SBP.

Karpowicz A. (2013). Świat liter. Typografia dla dzieci w perspektywie antropologii stowa, [w:] G. Leszczyński (red.), Stowo na terytorium sztuki dla dziecka, Poznań: Centrum Sztuki Dziecka w Poznaniu.

Klus-Stańska D. (2007). Między wiedzq a wtadzą. Dziecięce uczenie się w dyskursach pedagogicznych, „Problemy Wczesnej Edukacji”, Gdańsk: Uniwersytet Gdański, R. 3, nr 1/2, s. 92-106.

Lange G. (2007). Świat jest dziwny, Warszawa: Wydawnictwo Dwie Siostry.

Marciniak T. (1979). Plastyka zwierciadtem i wizją świata w życiu dziecka, [w:] M. Tyszkowa (red.), Sztuka dla dzieci szkolnych. Teoria - recepcja-oddziatywanie. Warszawa-Poznań: Wydawnictwo Naukowe PWN, s. 254-265.

Matoso M. (2015). Wytwórnik górą, tłum. J. Jankowski, Warszawa: Wydawnictwo Wytwórnia.

Mazepa-Domaga B., Wilk T. (2015). Edukacja w zakresie sztuk wizualnych, czyli o przygotowaniu dzieci $w$ mtodszym wieku szkolnym do odbioru i kreowania otaczajaccej je ikonosfery, „Chowanna”, t. 2(45), s. 89-104.

Pater-Ejgierd N. (2010). Kultura wizualna a edukacja, Poznań: Fundacja Tranzyt.

Rose G. (2010). Interpretacja materiatów wizualnych. Krytyczna metodologia badań nad wizualnościa, tłum. E. Klekot, Warszawa: Wydawnictwo Naukowe PWN. 
Sendak M. (2014). Tam, gdzie żyją dzikie stwory, tłum. J. Jędryas, Warszawa: Wydawnictwo Dwie Siostry.

Silverman D. (2008). Prowadzenie badań jakościowych, tłum. J. Ostrowska, Warszawa: Wydawnictwo Naukowe PWN.

Styszyńska J., Koziński M. (2015). Bieguny i ich zwykli - niezwykli mieszkańcy, Warszawa: Wodnokrąg.

Sztobryn S. (2007). Sztuka i jej przeżywanie w filozofii Johna Deweya, [w:] M. Zalewska-Pawlak (red.), Samotność oswojona przez sztukę, Łódź: Wydawnictwo Uniwersytetu Łódzkiego.

Sztompka P. (2012). Wyobraźnia wizualna i socjologia, [w:] M. Bogunia-Borowska, P. Sztompka (red.), Fotospoteczeństwo. Antologia tekstów z socjologii wizualnej, Kraków: Wydawnictwo Znak.

Szuman S. (1951). Ilustracje w książkach dla dzieci i mtodzieży. Zagadnienia estetyczne i wychowawcze, Kraków: Wiedza - Zawód - Kultura.

Uberman M. (2005), Alfabetyzacja kulturalna wprowadzeniem dziecka przedszkolnego w świat sztuki, [w:] R. Pęczkowski (red.), Polski system edukacji po reformie 1999 roku. Stan, perspektywy, zagrożenia, Poznań - Warszawa: Elipsa, s. 362-365.

Ungeheuer-Gołąb A. (2015). Obrazek na cate życie. O roli pierwszych obrazków/ilustracji $w$ życiu dziecka na przyktadzie autodoświadczania, „Chowanna”, t. 2 (45), Katowice: Wydawnictwo Uniwersytetu Śląskiego, s. 105-117.

\section{Netografia}

Bajtlik J. (2019). Portfolio, http://www.janbajtlik.com/?fbclid=IwAR19dY4oSsjE_ ChyH7JQwZfetHzcCq2CYB5KJzn_J50JKc-A1RtOSaDYUvI (dostęp: 10.01.2019).

Dylak S. (2012). Alfabetyzacja wizualna jako kompetencja wspótczesnego cztowieka, https:// repozytorium.amu.edu.pl/bitstream/10593/6035/1/Visual-literacy-M-E-K-2012.pdf (dostęp:12.12.2018).

Narodowe Centrum Kultury/GfK Polonia (2017). Między zabawa a sztuką. Wybory kulturalne opiekunów dzieci, https://www.nck.pl/badania/projekty-badawcze/raport-miedzy-zabawa-a-sztuka-wybory-kulturalne-opiekunow-dzieci (dostęp: 16.09.2018).

http://www.bolognachildrensbookfair.com/en/home/878.html (dostęp: 30.10.2018).

\section{ADRES DO KORESPONDENCJI}

mgr Joanna S. Ludwiczak

Wydział Nauk o Wychowaniu

Katedra Edukacji Artystycznej i Pedagogiki Twórczości

Uniwersytet Łódzki

e-mail: j.s.ludwiczak@gmail.com 